\title{
Recovery kinetics of winter stressed conifers: The effects of growth light environment,
}

extent of the season, and species.

Amy Verhoeven

\section{Introduction:}

In overwintering evergreen plants, the process of xanthophyll cycle-mediated
and absorgy dissipation changes from one that rapidly responds to alterations in ex
absorbed excitation energy in the summer months, to a long-term sustained engagement of energy dissipation that does not respond to a changing light
environment during winter (Verhoeven et al. 1998, 1999a; Adams et al. 2001, Öquis environment during winter (Verhoeven et al. 1998, 1999a; Adams et al. 2001, Öquis
and Huner 2003). The winter-induced sustained energy dissipation appears to be and Huner 2003). The winter-induced sustained energy dissipation appears to be
critical in maintaining the balance between light absorption and its reduced utilization due to low temperature effects on photosynthetic carbon reduction. This constormation of xanthophyll cycle characteristics appears to involve changes in the functional change from "light harvesting centers" to "dissipating centers" (Öquist and Huner 2003).

. study looking at its acclimation to low temperatures in a growth cabinet (Savitch et a 2002). Both studies demonstrated that winter acclimation involves decreases in the D1 protein of the PSII reaction center and its light harvesting complexes (LHCS), in xanthophyll cycle-mediated energy dissipation.

In addition to reorganization of the proteins within the photosynthetic apparatus, so studies have suggested that thylakoid protein phosphorylation may be involved in naintaining sustained energy dissipation. Correlations between sustained energy

dissipation and in photoinhibited leaves of the shade plant Monstera deliciesa been 1. 2001) and in the evergreen Douglas fir measured on subfreezing winter nights (Ebbert et al., 2005).

The goal of this study was to examine seasonal changes in the relative amount of all of (a)

the centers. Here we report preliminary data from this ongoing study examining the evergreen Balsam fir (Abies balsamea L. Mill.) growing in sun and shade
environments in the seasonally very cold climate of Saint Paul, Minnesota.

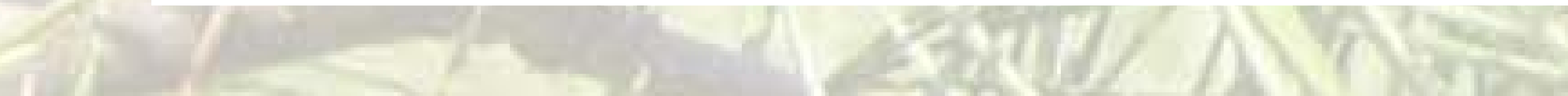 \\ Methods: \\ Four species of conifers (sun and shade needles) were monitored from November of 2007 through February of 2008: eastern white pine (Pinus strobus L.), balsam fir [Abies balsamea (L.) P. Milll, Taxus
cuspidata (L) and blue spruce (Picea pungens Engelm.). All plants were growing on the campus of the University of St. Thomas, in Saint Paut, Minnesota ( $\left(44^{\circ} 59^{\circ} 40^{\circ} \mathrm{N}, 93^{\circ} 05^{\prime} 35^{\circ} \mathrm{W}\right)$. For each species,
individual trees were sampled on each date. For pine, only sun needles were sampled, while for the individual trees were sampled on each date. For pine, only sun need
remaining three species both sun and shade needles were sampled. \\ Monitoring Recovery Kinetics of Winter-Stressed Needles
F/F, was measured on dark acclimated needles in the field. when all trees/shrubs had been in darkness for at least three hours. For each species, two meaa
were conducted on each of three trees/shrubs. After measuring Fv/Fm, the twig on which the measurement was nade was cut and placed in a Perri dish. After all samples were measured in the field $\mu$ mol photons $\mathrm{m}^{2} \mathrm{~s}^{-1}$.). Once indoors, all needles were organized in Pertid dishes with moist paper towels
where they were enaintained in constant conditions for up to six days. After the needles had warmed for thirty minutes, $\mathrm{F}_{/} / \mathrm{F}_{\mathrm{m}}$ was measured again to determine if tehre was any rapid component to the
Needles were subsequently measured after $1,10,24,48,72,96$ and 144 hours of recovery \\ Statistical Analysi \\ In order to determine if there was a rapid component to recovery, paired t-tests were performed on the and if there were differences between species in recovery response, data was analyzed after 24 hours and
log $\mathrm{F}_{\sqrt{ }} / \mathrm{F}_{\mathrm{m}}$ at time 0$)\left(0.8-\mathrm{F}_{\sqrt{\mathrm{m}}} / \mathrm{F}_{\mathrm{m}}\right.$ at time 0$)$. For shade needles, 0.84 was used instead of 0.8 , to indicate the

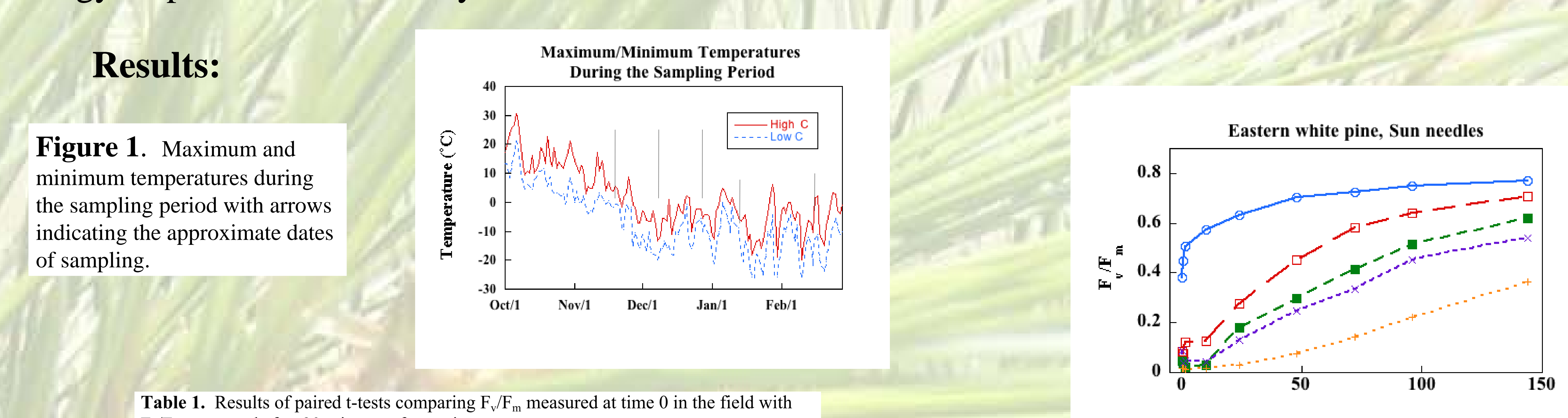

Figure ?. Recovery kinetics of Fv/Fm for all species. Time 0 was collected in the field after at least 3 hour of done on leaves maintained at room temperature and low

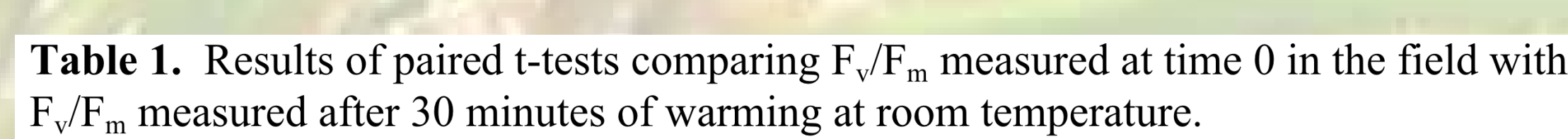

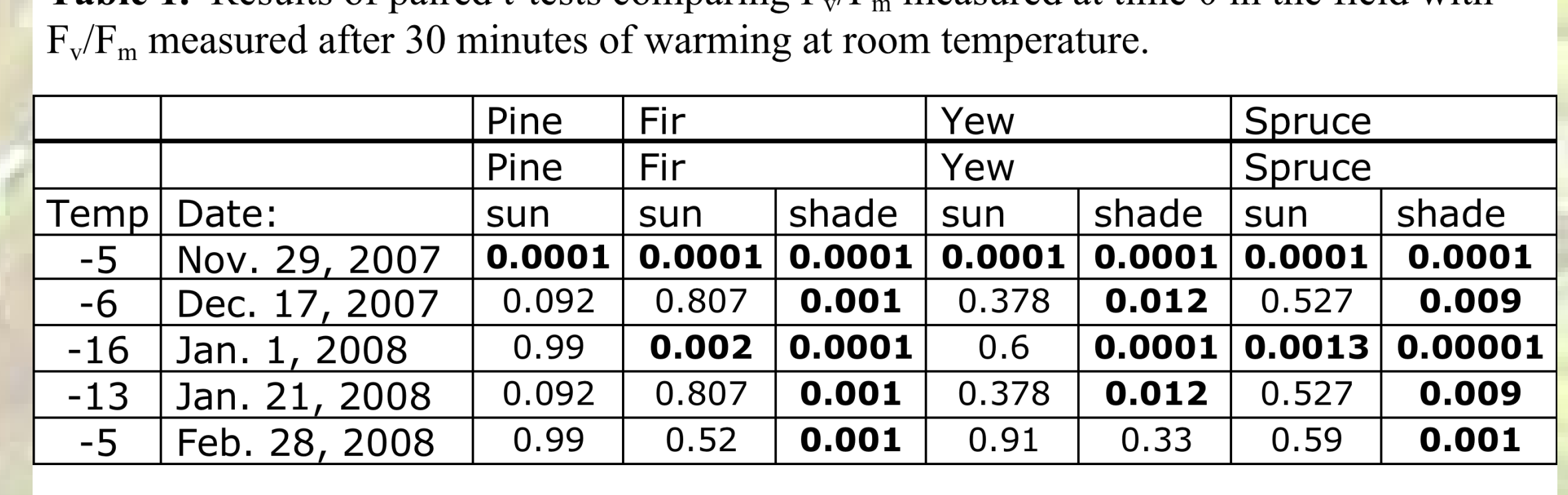

Figure 2. Percent
recovery aftet 24 (A) and
100 (B) hours of
recovery. For sun
needesles $100 \%$ recovery
was an Fv/Fm of 0.8
while for shade needles
the value was set at 0.84 .
The letters indicate if
there are significicant
differnces between
sampling dates within a
species.
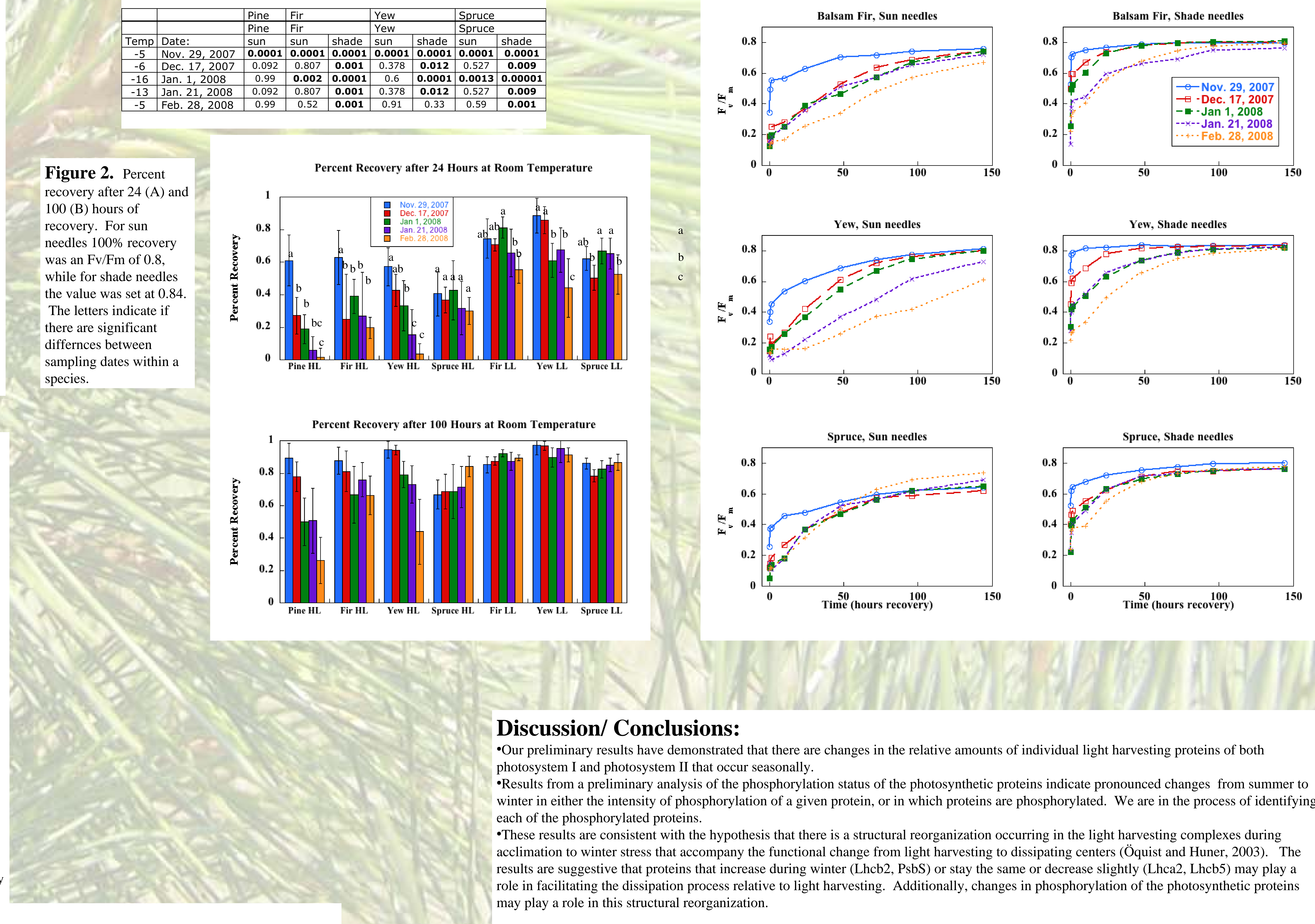

Discussion/ Conclusions:

photosystem I and photosysstem II that occur seasonally.

winter in either the intensity of phosphorylation of a given protein, or in which proteins are phosphorylated. We are in the process of identifying -These results are cyryated proteins.

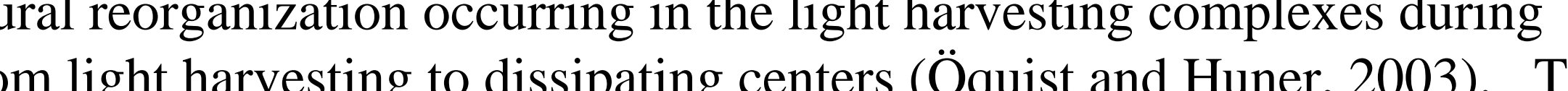
results are suggestive that proteins that increase during winter (Lhcb2. PshS) or stay the same or decrease slightly (Lhca2, Lhcb5) may play role in faciliat 